\title{
DIREITOS HUMANOS E A PRETENDIDA UNIVERSALIZAÇÃO
}

\author{
Sabrina Frigotto \\ Joel Haroldo Baade ${ }^{2}$ \\ Rodrigo Regert \\ Marcos Antônio Maestri Miguel \\ Recebido em 27/08/2020 \\ Aceito em 10/10/2020
}

\section{RESUMO:}

A história da humanidade é marcada por atos de desrespeito aos direitos da pessoa humana. Com a Segunda Guerra Mundial e o Holocausto, a Europa, através da Organização das Nações Unidas (ONU), buscou alternativas para valorizar e melhorar de forma significativa os direitos concernentes ao ser humano. A Assembleia Geral da ONU criou em 1948 a Declaração Universal dos Direitos Humanos, que visava promover tais direitos ao ser humano em caráter mundial. O presente artigo tem o objetivo de analisar a eficácia da aplicação dos Direitos Humanos, no Brasil, na África e no Oriente Médio. No Brasil a constituição garante aos cidadãos os direitos fundamentais. Na África e no Oriente Médio por outro lado, acabam se tornando exemplos de onde o Direito Internacional dos Direitos Humanos não consegue cumprir seu papel. Para esse fim, quanto aos aspectos metodológicos, a pesquisa pode ser classificada como de natureza básica, com abordagem qualitativa, objetivo exploratório e bibliográfica do tipo narrativa. Por fim, pôde-se chegar ao entendimento de que a tentativa de universalização dos direitos humanos permanece como utopia, pois a soberania nacional não se curvou aos direitos internacionais e, mesmo tendo ocorrido, em muitos casos, a prática contradiz o direito. Assim, também se torna difícil vislumbrar maior concreticidade quanto à efetividade dos direitos humanos em diferentes contextos.

PALAVRAS-CHAVE: Direitos Humanos. Brasil. Oriente Médio. África.

\section{HUMAN RIGHTS AND THE INTENDED UNIVERSALIZATION}

\section{ABSTRACT:}

The history of humanity is marked by acts of disrespect for the rights of the human person. With the Second World War and the Holocaust, Europe, through the United Nations (UN), search alternatives to significantly enhance the rights concerning the human being. The UN General Assembly created in 1948 the Universal Declaration of Human Rights, which aimed to promote such human rights worldwide. This article aims to analyze the effectiveness of human rights enforcement in Brazil, Africa and the Middle East. In Brazil the constitution guarantees citizens the fundamental rights. On the other hand, in Africa and the Middle East, they become examples of where international human rights law cannot fulfill its role. For this purpose, as for the methodological aspects, the research can be classified as basic in nature, with qualitative approach, exploratory and bibliographic

\footnotetext{
${ }^{1}$ Acadêmica do curso de Direito na Universidade Alto Vale do Rio do Peixe (UNIARP). E-mail: sabrinafrigotto19@gmail.com

${ }^{2}$ Doutor. Docente e pesquisador do Programa de Pós-Graduação em Desenvolvimento e Sociedade e do Programa Profissional em Educação da UNIARP. E-mail: baadejoel@gmail.com

${ }^{3}$ Mestre em Desenvolvimento e Sociedade pela UNIARP. Professor de Ensino Superior no Serviço Nacional de Aprendizagem Comercial (SENAC) - Videira e na UNIARP. E-mail: regert.rodrigo@gmail.com
} 
objective of narrative type. Finally, it could be understood that the attempt to universalize human rights remains a dream, since national sovereignty has not bowed to international rights and, even in many cases, the practice contradicts the law. Thus, it is also hard to find greater concreteness regarding the effectiveness of human rights in different contexts.

KEYWORDS: Human Rights. Brazil. Middle East. Africa.

\section{INTRODUÇÃO}

O mundo sempre contou com episódios de desrespeito aos direitos humanos. A escravidão, na antiguidade, é um exemplo claro desse fato. Entretanto, somente após a Segunda Guerra Mundial, com o Holocausto e a realidade nos campos de concentração nazistas, ocorreu uma mudança mais expressiva da comunidade internacional rumo a uma intervenção em realidade de desrespeito aos direitos humanos. Em 1948, a Assembleia Geral da Organização das Nações Unidas (ONU) criou a Declaração Internacional dos Direitos Humanos, com o objetivo de que barbáries como o Holocausto não voltassem a ocorrer.

Nessa perspectiva, o Direito Internacional dos Direitos Humanos, através de tratados e outras medidas, buscou relativizar a soberania estatal a fim de mostrar que os direitos da pessoa humana são de interesse global e não somente estatal.

O Brasil com a constituição de 1988, trouxe uma nova perspectiva de positivação dos direitos humanos no âmbito nacional. Ela ambiciona a criação de um Estado Democrático de Direito, no qual os objetivos principais são construir uma sociedade livre, erradicar a pobreza, reduzir as desigualdades e garantir o bem-estar de todos, sem preconceitos de qualquer origem. Em outros Estados nacionais, por seu turno, não se pode observar o mesmo desenvolvimento histórico, como é o caso de Estados na África e Oriente Médio.

Por conseguinte, esse artigo tem o objetivo de analisar a eficácia da aplicação dos Direitos Humanos, no Brasil, na África e no Oriente Médio. Visa analisar o porquê de alguns Estados ainda não conseguirem efetivar os direitos fundamentais do ser humano. Para isso, tem como base teórica, autores renomados como André de Carvalho Ramos, Sidney Guerra, Flávia Piovesan e Valerio de Oliveira Muzzuoli que trazem análises do direito internacional. Além de autores de artigos como Victor Insali e Thatiana Dias Vaconcelos Dal Col.

O Oriente Médio e o Continente Africano são o foco central da análise. O estudo de suas relações religiosas, sociais e morais ajudará na compreensão do motivo pelo qual nesses lugares os Direitos Humanos são negligenciados.

Quanto à estrutura da análise, o artigo foi pensado em cinco momentos. No primeiro é apresentado o significado de Direitos Humanos; no segundo, aborda-se os Direitos Humanos no Brasil; 
no terceiro, a Internalização e Universalização dos Direitos Humanos são objeto de compreensão; no quarto, descreve-se a perspectiva dos Diretos Humanos na África; e, por fim, estuda-se os Direitos Humanos no Oriente Médio.

\section{O QUE SÃO OS DIREITOS HUMANOS}

O século XX foi marcado por tragédias, provindas de conflitos globais. A Segunda Guerra Mundial tornou-se um marco no desrespeito aos direitos da pessoa humana, principalmente na Alemanha nazista. No pós-guerra, a ideia de soberania nacional foi contestada, visto que o ser humano possui direitos inerentes a sua existência (PIOVESAN, 2017).

Neste cenário, em 22 de abril de 1945, nasce a ONU, que tem por objetivo a manutenção da paz e da segurança internacional, além da proteção e valorização humana. Tal marco deu início à fase legislativa dos direitos humanos e com ela a produção de vários tratados internacionais como a Declaração Universal dos Direitos Humanos, o Pacto de Direitos Civis e Políticos e a Convenção sobre os Direitos da Mulher (GUERRA, 2015).

É justamente sob o prisma da reconstrução dos direitos humanos que é possível
compreender, no Pós-Guerra, de um lado, a emergência do chamado Direito
Internacional dos Direitos Humanos, e, de outro, a nova feição do Direito
Constitucional ocidental, em resposta ao impacto das atrocidades então cometidas. No
âmbito do Direito Constitucional ocidental, são adotados Textos Constitucionais
abertos a princípios, dotados de elevada carga axiológica, com destaque para o valor
da dignidade humana (PIOVESAN, 2017, p. 103).

A proteção internacional dos direitos humanos assegura uma garantia de direitos ao nativo e ao estrangeiro em qualquer lugar, condição ou tempo. São estabelecidas, a partir daí, medidas que visam à contenção de abusos por parte dos países, já que o Estado é o maior violador desses direitos (GUERRA, 2017).

Entretanto, foi somente em 1948 que a Assembleia Geral das Nações Unidas aprovou a Declaração Universal dos Direitos Humanos, inspirada na Carta de São Francisco de 1945. Essa Declaração estabelece que todos as pessoas nascem livres e iguais em dignidade e direitos, como também, que não podem sofrer distinções de qualquer espécie. De acordo com a Carta da ONU, uma Resolução da Assembleia Geral sobre tal assunto não possui força vinculante, o que impulsionou os trabalhos de redação de novos tratados internacionais (RAMOS, 2016).

Posteriormente à criação da Declaração, surge o Pacto de Direitos Civis e Políticos. Significa dizer que para a garantia plena dos primeiros direitos é necessário que estes sejam reconhecidos e garantidos pelo Estado. Assim os Estados devem assumir o compromisso de criar legislações que respeitem, assegurem e deem efetividade para os indivíduos que estejam em seu 
território, sob sua jurisdição, aos direitos previstos no pacto internacional. Colocou-se, dessa forma, o ser humano em uma posição que antes era reservada somente ao Estado, elevando-o à categoria de sujeito do direito internacional público (MAZZUOLI, 2018).

Existem muitas dificuldades para que ocorra uma proteção efetiva aos direitos humanos internacionalmente. Há muitas críticas com relação à real definição de direitos humanos, um compilado único com quais são realmente esses direitos e os mecanismos para implementá-los.

Geralmente a expressão "direitos humanos" é empregada para denominar tanto os direitos positivados nos documentos internacionais, como também as exigências básicas relacionadas à dignidade, liberdade e igualdade de pessoa que não alcançaram um estatuto jurídico positivo (GUERRA, 2015, p. 139).

Os direitos humanos diferem da ideia de direitos naturais e não devem ser entendidos como sinônimos. O direito natural, ainda que viável, nem sempre encontra validade (PIOVESAN, 2017).

\section{DIREITOS HUMANOS NO BRASIL}

O ano de 1988 foi de transição no cenário brasileiro, o regime democrático chegou ao poder e uma nova constituição foi promulgada para quebrar completamente os resquícios de Ditadura Militar. A Constituição de 1988 foi considerada uma das melhores do mundo na época, projeta a construção de um Estado Democrático de Direito, e tem por objetivo assegurar o exercício dos direitos individuais, a segurança, a liberdade, o bem estar, a igualdade e a justiça como valores principais para uma sociedade em progresso (DAL COL, 2010).

$\mathrm{O}$ art. $3^{\circ}$ da constituição brasileira aponta os principais objetivos do Estado, que são construir uma sociedade livre, justa e solidária, erradicar a pobreza, promover o desenvolvimento nacional, reduzir as desigualdades, bem como, garantir o bem-estar de todos, sem preconceitos de qualquer origem. Essa foi a primeira vez que uma constituição brasileira listou os principais deveres do Estado para com a proteção da dignidade da pessoa humana (PIOVESAN, 2017).

\footnotetext{
Seja no âmbito internacional, seja no âmbito interno, a dignidade da pessoa humana é princípio que unifica e centraliza todo o sistema normativo, assumindo especial prioridade. A dignidade humana simboliza, desse modo, verdadeiro superprincípio constitucional, a norma maior a orientar o constitucionalismo contemporâneo, nas esferas local e global, dotando-lhe de especial racionalidade, unidade e sentido (PIOVESAN, 2017, p. 105).
}

A Carta de 1988 assegura também os direitos coletivos e difusos, pertinentes à determinada categoria ou classe social. Essa constituição trouxe ao Brasil um novo parâmetro para os 
direitos fundamentais do cidadão, inovando de maneira positiva, o cenário político-constitucional brasileiro (GUERRA, 2017).

\title{
4 INTERNACIONALIZAÇÃO E UNIVERSALIZAÇÃO DOS DIREITOS HUMANOS
}

Em 1920, a Liga das Nações criou um programa internacional de proteção às minorias e direito ao trabalho. Dessa forma, relativizou a soberania estatal, pois os países eram obrigados a cumprir o que foi imposto pela instituição. Os que desrespeitassem o programa poderiam sofrer sanções econômicas e militares (PIOVESAN, 2017).

A Organização Internacional do Trabalho (OIT) também teve papel fundamental da universalização dos direitos humanos. Propôs condições internacionais de trabalho digno, com a finalidade de promover o bem-estar. Foi criada após a Primeira Guerra Mundial e, em apenas sessenta anos, já contava com mais de cem convenções as quais os Estados passaram a apoiar (PIOVESAN, 2017).

Todavia, o Direito Internacional dos Direitos Humanos somente surgiu e se consolidou após a Segunda Guerra Mundial. Frente às atrocidades cometidas no período nazista, a necessidade de uma internacionalização dos direitos fundamentais tornou-se evidente. Surgiu assim a ideia de que os Direitos Humanos não deveriam basear-se somente na atuação soberana de um Estado, pois é um tema de interesse internacional. A violação desses direitos não é um problema nacional, mas global (RAMOS, 2016).

\begin{abstract}
A Assembleia Geral proclama a presente Declaração Universal dos Direitos Humanos como o ideal comum a ser atingido por todos os povos e todas as nações, com o objetivo de que cada indivíduo e cada órgão da sociedade, tendo sempre em mente esta Declaração, se esforce, através do ensino e da educação, por promover o respeito a esses direitos e liberdades, e, pela adoção de medidas progressivas de caráter nacional e internacional, por assegurar o seu reconhecimento e a sua observância universal e efetiva (Assembleia Geral da ONU, 1948).
\end{abstract}

O Direito Internacional dos Direitos Humanos possui algumas peculiaridades: versa sobre os direitos de todos, sem distinções quanto à nacionalidade, opção política, credo e outras especificidades; os Estados assumem responsabilidades e deveres em prol dos indivíduos; os indivíduos têm acesso a instâncias internacionais de supervisão e controle das obrigações do Estado, sendo criado um conjunto de sofisticados processos internacionais de direitos humanos (RAMOS, 2016).

Na atualidade, a prática é um pouco distinta da teoria, visto que existem muitos Estados na África e no Oriente Médio, por exemplo, em que os direitos humanos são desrespeitados e há poucas 
evidências quando à ingerência da comunidade internacional para a mudança desta realidade.

\section{DIREITOS HUMANOS NA ÁFRICA}

A Carta Africana dos Direitos Humanos e dos Povos, mais conhecida como Carta de Banjul, foi aprovada em 1981 pela Conferência Ministerial da Organização da Unidade Africana (OUA) em Banjul, capital da Gâmbia. A União Africana, antiga Organização da Unidade Africana, engloba todos os Estados africanos, com exceção do Marrocos (RAMOS, 2016).

Os propósitos fundamentais da Carta Africana são a proteção da soberania dos Estados, a integração social e econômica do continente, a integridade do território e o respeito aos direitos humanos. O sistema africano, além de sua Carta, possui outros documentos ligados a direitos fundamentais, como a Carta Africana sobre os direitos e bem-estar da criança (GUERRA, 2015).

O sistema de proteção aos direitos humanos é de suma importância nessa região, pelo fato de já ter sido palco de múltiplas atrocidades com relação a esses direitos. O texto criado na África difere do presente nos continentes americano e europeu, pois dá preferência aos direitos dos povos em detrimento aos direitos civis (GUERRA, 2015).

Contudo, ainda são encontrados muitos entraves para que a aplicação te tais medidas no continente tornem-se efetivas. Isso porque a Carta Africana, que é uma lei internacional, fica dependente do desenvolvimento político e constitucional dos Estados (INSALI, 2010).

A Comissão Africana dos Direitos Humanos e dos povos é o órgão incumbido de proteger os direitos humanos coletivos e individuas, tem ainda a função de interpretar a Carta Africana de Direitos Humanos e dos Povos, além de punir os que a violarem (RAMOS, 2016).

\footnotetext{
A África apresenta vários problemas para que o referido texto possa ser efetivamente implementado: i) falta de recursos financeiros; ii) falta de interesse político por alguns Estados; iii) falta de maturidade política; iv) falta de unidade; v) falta do desenvolvimento de maior cultura dos direitos humanos; vi) falta de desenvolvimento econômico e social (GUERRA, 2015, p. 167).
}

A África possui vários problemas que impedem que as medidas presentes na Carta sejam aplicadas. Devido à extensão territorial, a falta de unidade é uma dessas adversidades, assim como a falta de recursos financeiros, de desenvolvimento social e econômico. Enfrenta-se também dificuldades ligadas à pobreza, como a fome, doenças e o analfabetismo. Todavia, a imaturidade política e a falta de interesse por parte dos Estados são os principais aspectos que possibilitam a estagnação do continente no que se refere a políticas mais efetivas para a concretização dos direitos humanos (INSALI, 2010). 
A Carta de Banjul buscou um caminho próprio, mesclando os valores universais aos valores regionais, estabelecendo, em seu preâmbulo, que "as virtudes das suas tradições históricas e os valores da civilização africana" devem "inspirar e caracterizar as suas reflexões sobre a concepção dos direitos humanos e dos povos" (RAMOS, 2016, p. 276).

A Carta de 1981, baseada na cultura do local, encontra ainda muitos empecilhos para ser colocada em prática. Isso ocorre pela falta de comprometimento dos Estados e da própria Comissão Africana, que enfrenta graves crises financeiras. A falta de empenho da Comissão gera um sentimento de impunidade geral, já que os Estados não se veem na obrigatoriedade de cumprir com suas incumbências frente à garantia e proteção dos direitos humanos (RAMOS, 2016).

\footnotetext{
Além da falta de estrutura e atuação limitada a poucos casos, a Comissão ainda fica debilitada pela ausência de mecanismos que assegurem o cumprimento de suas recomendações pelos Estados infratores. Parte da doutrina chega a mencionar a "futilidade" de se recorrer à Comissão, caso não haja supervisão mais robusta do cumprimento de suas conclusões. Assim, o mecanismo quase judicial da Carta da Banjul ressente-se da falta de força vinculante (RAMOS, 2016, p. 279).
}

Além da falta de estrutura e atuação limitada a poucos casos, a Comissão ainda fica debilitada pela ausência de mecanismos que assegurem o cumprimento de suas recomendações pelos Estados infratores. Parte da doutrina chega a mencionar a "futilidade" de se recorrer à Comissão, caso não haja supervisão mais robusta do cumprimento de suas conclusões. Assim, o mecanismo quase judicial da Carta da Banjul ressente-se da falta de força vinculante (RAMOS, 2016, p. 279).

\section{DIREITOS HUMANOS NO ORIENTE MÉDIO}

O Oriente Médio é, de forma recorrente, alvo de ataques quando o tema em voga é a igualdade e os direitos das pessoas. Tal fato ocorre porque países que compõe esse território têm política que ferem os direitos humanos com relação a alguns grupos, como por exemplo, mulheres ou pessoas que seguem crenças religiosas minoritárias. É necessário então observar alguns dos principais países do Oriente Médio para entender qual a realidade vigente nessa sociedade tão complexa.

O sistema árabe de direitos humanos possui A Carta Árabe de Direitos do Homem, de 1994 e a Declaração Universal Islâmica de Direitos Humanos, promulgada em 1981, documentos que deveriam garantir a efetividade desses direitos (GUERRA, 2015).

Para essa sociedade os direitos humanos estão centrados no poder e na vontade de Deus, assim, o cunho jurídico referente à proteção dos direitos fundamentais é deixada a parte. O Islã busca imitar o exemplo de Maomé, contudo reverenciá-lo acaba preparando o terreno para atos de violência, uma vez que esse culto ao profeta inclui os relatos violentos do Alcorão, como as campanhas militares de Maomé. Esse fato, sem dúvidas, gera efeitos muito negativos para o povo árabe, em especial para 
as mulheres (FARIAS, 2018).

Os direitos humanos, em regra, para os povos árabes, apresentam-se como um poder derivado do poder divino, o que acaba por produzir situações complexas para alguns segmentos da população, como no caso das mulheres (GUERRA, 2015, p. 176).

A Arábia Saudita proíbe as mulheres de dirigirem e pouquíssimas trabalham, apenas 5\% do total. A discriminação desta parcela da população levou à caracterização desse fenômeno como “apartheid de gênero" (NAIMI, 2016).

A Declaração Universal Islâmica de Direitos Humanos afirma que o Islã possui um “código ideal" de direitos humanos, sendo eles a Sunnah e o Corão. Para esses povos, Deus é o único e verdadeiro legislador. Assim, nenhum governante ou autoridade política é capaz de questionar ou revogar essa "lei divina" (GUERRA, 2015).

O Irã é lembrado pela revolução de 1979, que ficou conhecida por instaurar no país um governo caracterizado por muitos como "pior do que o anterior". Os adeptos a religiões não aceitas pelo governo são duramente perseguidos e privados do direito à liberdade, não podem cursar uma faculdade ou trabalhar. A mulher iraniana necessita da autorização de seu pai ou responsável do sexo masculino para casar e até mesmo para emitir um passaporte. Em alguns cursos universitários é proibido o ingresso de mulheres (NAIMI, 2016).

Segundo Farias (2018), países islâmicos, em geral, tem baixos índices de direitos humanos, principalmente no aspecto religioso. $\mathrm{O}$ islamismo discrimina membros de outras crenças $\mathrm{e}$ não permite a conversão de membros do Islã a outras religiões. A violação dessas leis pode gerar deportação, castigos físicos e até prisão.

Os demais países do território, como a Síria e Israel, não fogem muito dos fatos apontados anteriormente. Vários destes Estados apresentam pena de morte, os direitos de lésbicas, gays, bissexuais e transexuais são inexistentes. As mulheres são tratadas com brutal desigualdade e somente é permitido cultuar religiões reconhecidas pelo governo (NAIMI, 2016).

\section{CONSIDERAÇÕES FINAIS}

A Declaração Universal dos Direitos Humanos foi criada após a Segunda Guerra Mundial, em um momento onde todos ficaram escandalizados com o horror nazista. O Brasil revolucionou o âmbito constitucional com sua Carta de 1988 ao criar a perspectiva de em Estado Democrático de Direito. Seus principais objetivos eram assegurar o exercício dos direitos individuais, a segurança, a liberdade, o bem-estar, a igualdade e a justiça como valores principais para uma sociedade em progresso. 
A tentativa de universalização dos Direitos Humanos também ocorreu no pós-guerra. Visava à relativização da soberania estatal, para que, dessa forma, fosse possível que as pessoas do mundo todo tivessem seus direitos fundamentais garantidos.

Infelizmente isso não se tornou efetivo. Ainda hoje muitos Estados, principalmente os localizados na África e no Oriente Médio, sofrem o desrespeito de seus direitos. Na África a pobreza e a inexistência de unidade, bem como a dificuldade de implantar o conteúdo da Carta Africana na prática e o desleixo de boa parte dos Estados, impossibilita uma realidade diferente da atual.

No Oriente Médio o fundamentalismo religioso inviabiliza um convívio pacífico entre a população. Mulheres, homossexuais, pessoas que seguem outras religiões, todos duramente perseguidos e punidos por simplesmente ser quem são. $\mathrm{O}$ Estado não consegue positivar muitas medidas para que a realidade mude, já que para esses povos o único e verdadeiro legislador é Deus.

Muito já foi conquistado para os direitos humanos desde 1945, entretanto a universalização ainda está longe de ser alcançada. O horror da Segunda Guerra mostrou ao mundo que medidas deveriam ser tomadas, esse marco possibilitou a criação da ONU. Mas ainda hoje, observase em diferentes contextos a violação dos direitos humanos, seja nos Estados que os reconhecem em suas legislações ou nos que se orientam por outros princípios. Desse modo, tanto no Brasil, como na África e Oriente Médio precisa-se falar e pensar em Direitos Humanos.

A problemática dos Direitos Humanos continua atual em todos os lugares e diz respeito a humanidade como um todo. A sua abrangência e validade precisam igualmente de reflexão. Enfim, trata-se de tema longe de ser esgotado.

\section{REFERÊNCIAS}

GUERRA, Sidney. Direitos humanos curso elementar. São Paulo: Saraiva, 2017.

GUERRA, Sidney. Direito internacional dos direitos humanos. São Paulo: Saraiva, 2015.

INSALI, Victor. A proteção dos direitos e liberdades fundamentais na carta africana dos direitos do homem e dos povos. 2010. 198 f. Dissertação Mestrado em Direito - UFBA, Universidade Federal da Bahia, Salvador.

PIOVESAN, Flávia. Direitos humanos e o direito constitucional internacional. São Paulo: Saraiva, 2017.

RAMOS, André de Carvalho. Processo Internacional de Direitos Humanos. São Paulo: Saraiva, 2016.

RAMOS, André de Carvalho. Teoria geral dos direitos humanos na ordem internacional. São Paulo: Saraiva, 2016. 
FARIAS, Igor Henrique Sabino de. Deslocados internos por perseguição religiosa e o Estado islâmico: uma análise do caso iraquiano (2006-2014). 2018. 127 f. Dissertação Mestrado em Relações Internacionais - Universidade Estadual da Paraíba, João Pessoa.

NAIMI, Shervin. Uma análise dos direitos fundamentais sob ameaça no âmbito do Direito Internacional Público e à luz da Declaração Universal dos Direitos Humanos da ONU. São Paulo, 2016. Disponível em: <https://shervinnaimi.jusbrasil.com.br/>. Acesso em: 22 jul. 2019.

DAL COL, Thatiana Dias Vasconcelos. Dinâmicas e mecanismos de proteção e defesa dos direitos humanos no estado brasileiro - a CDHM e a SEDH. 2010. 167 f. Dissertação Programa de Pós-Graduação em Ciências Sociais com especialização em estudos comparados sobre as Américas - Universidade de Brasília, Brasília.

MAZZUOLI, Valerio de Oliveira. Curso de direitos humanos. São Paulo: Forense, 2018. 